\title{
A two parameter model for prediction of crop loss by weed competition from early observations of relative leaf area of the weeds
}

\author{
By M J KROPFF ${ }^{1,4 *}$, L A P LOTZ $^{2}$, S E WEAVER ${ }^{3}, \mathrm{H} \mathrm{J} \mathrm{BOS}^{4}, \mathrm{~J} \mathrm{WALLINGA}^{4}$ \\ and $\mathrm{T} \mathrm{MIGO}^{1}$ \\ ${ }^{1}$ International Rice Research Institute, $P$ O Box 933, 1099 Manila, The Philippines \\ ${ }^{2}$ Centre for Agrobiological Research, P O Box 14, 6700 AK Wageningen, The \\ Netherlands \\ ${ }^{3}$ Agriculture Canada, Research Station Harrow, Ontario, Canada NOR $1 G 0$ \\ ${ }^{4}$ Department of Theoretical Production Ecology, Wageningen Agricultural \\ University, P O Box 430, 6700 AK Wageningen, The Netherlands
}

(Accepted 20 January 1995)

\begin{abstract}
Summary
The recently introduced empirical model for early prediction of crop loss by weed competition based on the relative leaf area of the weeds shortly after crop emergence (Kropff \& Spitters, 1991), assumes a maximum yield loss of $100 \%$ at high weed infestations. This is biologically not realistic. If weeds have a shorter life cycle than the crop, when they emerge much later than the crop or when they are unable to overtop the crop, maximum yield loss at high weed infestations is expected to be less than $100 \%$. A two parameter model is introduced in this paper that accounts for a variable maximum crop yield loss by weed competition. The parameters are the "relative damage coefficient" $q$, and a parameter that describes the maximum yield loss caused by the weeds $(m)$. The one and two parameter models were evaluated with data on the effects of weeds on rice, sugarbeet and tomato.

Both models were able to describe the data on the effect of different weed densities and periods between crop and weed emergence fairly well. The introduction of the second parameter resulted in a significantly better description of observed data in five out of nine datasets. The value of the parameter $q$ depends on the time of observation of the relative leaf area. The change in the value of $q$ in time could be estimated from the difference in relative growth rate of the species. The accuracy of this estimation is strongly determined by the variability in the relative growth rate of the leaf area of single plants. Possibilities for scientific and practical application of the model are discussed.
\end{abstract}

Key words: Competition, model, Monochoria vaginalis (Burm. f.) Presl, Echinochloa crus-galli L. (Beauv.), rice, sugarbeet, tomato, Chenopodium album L., Stellaria media L., Polygonum persicaria L., Solanum ptycanthum Dun.

\section{Introduction}

A simple empirical model for early prediction of crop losses by weed competition was introduced by Kropff \& Spitters (1991). This model relates yield loss to relative leaf area

* Corresponding author

(C) 1995 Association of Applied Biologists 
index of weeds (expressed as leaf area index weeds/leaf area index crop+weeds) shortly after crop emergence using the "relative damage coefficient $(q)$ " as the single model parameter. In spite of its simplicity, the model described results for several crop weed combinations with different densities and periods between crop and weed emergence quite accurately (Kropff \& Spitters, 1991; Kropff, Weaver \& Smits, 1992).

This one parameter model assumes a yield loss of $100 \%$ at high weed infestations. However, in several studies a clear maximum yield loss at high weed densities has been reported ( $c f$. Cousens, 1985; Weaver, Smits \& Tan, 1987), an effect that should be accounted for by the model to provide accurate predictions in such situations. Therefore, an extended version of the model presented by Kropff \& Spitters (1991) was developed that accounts for a variable maximum yield loss by weeds. Since there were very few data in appropriate form available, experiments were conducted in tropical and temperate environments in order to provide suitable data for model evaluation. Both models were evaluated using the datasets from the experiments.

\section{Materials and Methods}

\section{The model}

The one parameter model for the prediction of yield loss from the relative leaf area of the weeds introduced by Kropff \& Spitters (1991), was derived from the hyperbolic yieldloss weed density equation. The equation was derived from the general model for plant competition described by Spitters (1983), which can be simplified to a one parameter model for crop loss by weed competition (Spitters, Kropff \& de Groot, 1989):

$$
Y L=\frac{i N_{w}}{1+i N_{w}}
$$

in which $Y L$ gives the yield loss, $N_{\mathrm{w}}$ is the weed density and $i$ describes the yield loss per weed per $\mathrm{m}^{2}$ as weed density approaches 0 . In this one-parameter model maximum yield loss is 1 (or $100 \%$ ) at high weed densities.

Cousens (1985) introduced a similar two parameter model:

$$
Y L=\frac{i N_{w}}{1+\frac{i}{m} N_{w}}
$$

where $m$ is the maximum yield loss at infinite density. These hyperbolic yield-density equations fit very well to data from additive experiments in which only the weed density is varied (Kropff, Vossen, Spitters \& de Groot, 1984; Cousens, 1985; Weaver et al., 1987; Spitters et al., 1989; Kropff et al., 1992). In some situations the extra parameter for maximum yield loss (Eqn 2) was needed to obtain an accurate description of the data by the model (Cousens, 1985; Weaver et al., 1987). However, model parameters may vary strongly among experiments due to the effect of other factors on competition processes. One of the most important factors causing this variation is the period between crop and weed emergence (Cousens, Brain, O’Donovan \& O'Sullivan, 1987; Håkansson, 1983; Kropff et al., 1992). Some workers introduced an additional variable in the hyperbolic yield-density equation to account for the effect of differences in the period between crop - and weed emergence 
(Håkansson, 1983; Cousens et al., 1987). This approach has a biologically sound basis. However, its practical application on a farm to predict yield loss shortly after crop emergence on the basis of observations of weed emergence and density does not seem to be realistic. It requires a daily count of the numbers of weeds emerging, since the date of weed emergence may be a very sensitive factor (Kropff et al., 1992). In addition, weed species often emerge in successive flushes, making it difficult to determine the relative time of weed emergence without treating the flushes as different weed species.

A new, simple empirical model for early prediction of crop losses by weed competition was introduced by Kropff \& Spitters (1991). It was mathematically derived from the well tested hyperbolic yield density model by substituting $L A I / L A$ for $N$ (which is leaf area index divided by the leaf area per plant). This model relates yield loss to the relative leaf area index of weeds ( $L_{w}$ expressed as leaf area index weeds/leaf area index crop+weeds) shortly after crop emergence using the "relative damage coefficient" $q$ as the single model parameter:

$$
Y L=\frac{q L_{w}}{1+(q-1) L_{w}}
$$

The mathematical derivation was given by Kropff \& Spitters (1991). The model accounts for the density effect because it was directly derived from Eqn 1, but it was demonstrated that the model also accounts for (part of) the effect of the period between crop and weed emergence (Kropff \& Spitters, 1991).

The value of $q$ for a given crop weed combination changes with the period between crop emergence and the moment of observation of the relative leaf area index when the species have a different relative growth rate of the leaf area. A simple theoretically derived relationship that accounts for this effect was presented by Kropff \& Spitters (1991):

$$
q=q_{0} \exp \left[\left(R G R L_{c}-R G R L_{w}\right) t\right]
$$

where $R G R L$ is the relative growth rate of the leaf area $\left({ }^{\circ} \mathrm{C}^{-1} \mathrm{day}^{-1}\right), t$ is the time expressed in degree days $\left({ }^{\circ} \mathrm{Cd}\right)$ and $q_{0}$ is the value of $q$ when $L_{\mathrm{w}}$ is observed at $t=0$ (the moment of observation for which the relative damage coefficient $q$ has been determined from experimental data) and $t$ indicates the period between $t=0$ and the time (in degree days) for which the relative damage coefficient $q$ is calculated. When the weeds and the crop have the same $R G R L$, the relative damage coefficient $q$ will not change in time. This approach is based on the assumption that freely growing young plants grow exponentially.

However, the model assumes a maximum yield loss of $100 \%$ at high weed infestations, which may not be realistic. An extended version of Eqn 3 can be derived that accounts for a variable maximum yield loss $(m)$ caused by weeds at high densities (for mathematical derivation see Appendix I):

$$
Y L=\frac{q L_{w}}{1+\left(\frac{q}{m}-1\right) L_{w}}
$$

(Note the analogy between the weed density models (Eqns 1 and 2) and the relative leaf area models (Eqns 3 and 5). For a multispecies competition situation Eqn 5 results in:

$$
Y L=\frac{\Sigma q_{i} L_{w, i}}{1+\Sigma\left(\frac{q_{i}}{m_{i}}-1\right) L_{w, i}}
$$




\section{Experimental method}

The model was evaluated using data on the effect of Monochoria vaginalis (Burm. f.) Presl and Echinochloa crus-galli L. (Beauv.) on transplanted rice (Oryza sativa L.) Chenopodium album L., Stellaria media L. and Polygonum persicaria L. on sugarbeet (Beta vulgaris L.) and the data published by Weaver et al. (1987) on the effect of Solanum ptycanthum Dun. on direct seeded and transplanted tomatoes.

\section{Experiment 1}

The effect of different densities and dates of emergence of $M$. vaginalis and $E$. crus-galli on rice production was studied in 1991 in the wet season on the experimental farm of the International Rice Research Institute at Los Baños, Philippines. The experiment was fully irrigated and optimally supplied with nutrients according to local recommendations. Rice was grown on hills with three plants per hill at $20 \mathrm{~cm} \times 20 \mathrm{~cm}$ spacing. Seedlings were transplanted on 8 August and harvested on 19 November. Pre-germinated weed seeds were broadcast at $0,20,40,60$ and 80 plants per $\mathrm{m}^{2}$ at 5 and 22 days after transplanting. Established weed densities were considerably lower. Leaf area of the crop and the weeds was measured by destructive sampling at 22,36 and 58 days after transplanting.

\section{Experiment 2}

Field experiments with sugarbeet and the weeds $C$. album, S. media and $P$. persicaria were conducted in 1990 on a sandy loam soil at Droevendaal Experimental Station of the Centre for Agrobiological Research at Wageningen, The Netherlands. The sugarbeet crop was grown at a density of 110000 plants per ha at a spacing of $0.5 \mathrm{~m}$ between the rows and $0.18 \mathrm{~m}$ within the row. The weeds were seeded by hand, after pre-germination in a growth cabinet, at 5,10 or 15 days after crop emergence and thinned to different densities (Table 1 ). The effect of a mixture of $C$. album and $S$. media was studied for the same periods between crop and weed emergence, but with each weed species established at half the weed density in the single weed species plots. Other weeds were removed by hand. Leaf area index of the crop and weeds was measured by destructive sampling at 10, 16, 23 and 42 days after crop emergence (only data from 23 days after emergence are reported here). The crop was sown on 6 April and harvested on 2 October.

Table 1. Weed densities observed in the 1990 experiment with sugarbeet and three weed species

Period between crop and weed emergence (days)

Chenopodium album

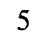

10
15

2.8
5.6
11.1
2.8
5.6
22.2
2.8
11.1
44.4

$\begin{array}{cr}\begin{array}{c}\text { Stellaria media } \\ \text { numbers } \mathrm{m}^{-2}\end{array} & \text { Polygonum persicaria } \\ & \\ 2.8 & 2.8 \\ 11.1 & 22.2 \\ 88.9 & 44.4 \\ 2.8 & 2.8 \\ 11.1 & 22.2 \\ 88.9 & 44.4 \\ 2.8 & 5.6 \\ 22.2 & 23.3 \\ 88.9 & 88.9\end{array}$




\section{Experiment 3}

Data on the effects of $S$. ptycanthum on direct seeded and transplanted tomatoes and a complete account of experimental methods were originally published by Weaver et al. (1987). Transplanted and direct seeded H2653 tomatoes were grown on a sandy loam soil at the Agriculture Canada, Research Station, Harrow, Ontario in 1984 and 1985 at a density of 16700 plants per ha. Transplanting and direct seeding was in mid May for both years. Transplants were approximately $6 \mathrm{wk}$ old and at the four leaf stage of development at transplanting. Weed densities were established by thinning natural populations of $S$. ptycanthum to $0,0.25,0.5,1,2,4,8,16$ or 32 plants per $\mathrm{m}^{-2}$. Yields of transplanted tomatoes were measured in early August and those of seeded tomatoes in late August. Leaf area per plant of the weeds and the crop were estimated at 200 degree days after transplanting or sowing (about 27 days) using a simulation model (Kropff et al., 1992). Leaf area index was obtained by multiplying the simulated leaf area per plant with the crop and weed density.

\section{Model comparison}

The two models (Eqns 3 and 5) were compared with respect to their accuracy in describing the experimental data. The residual sums of squares from non-linear regression of the one and two parameter model (Eqns 3 and 5) were recorded and compared statistically by an F-test: the ratio between the difference in the residual sums of squares divided by the difference in degrees of freedom and the ratio of residual sum of squares and the degrees of freedom of the two parameter model:

$$
\mathrm{F}=\frac{(\mathrm{RSS} 1-\mathrm{RSS} 2) /(\mathrm{DF} 1-\mathrm{DF} 2)}{\mathrm{RSS} 2 / \mathrm{DF} 2}
$$

\section{Results and Discussion}

\section{Model performance}

The relationship between the relative leaf area index of $M$. vaginalis and $E$. crus-galli and yield loss in rice is presented in Fig. 1. The data are given for individual plots and not for means of replicates, as the establishment of pre-set densities was not achieved. Therefore, and because of the complex nature of competition, the data show a large variability. For both crop weed combinations the two parameter model showed a better fit to the data that suggest a maximum yield loss $m$ at high weed infestations. A significant reduction in the residual sums of squares was observed by introducing the parameter $m$ (Table 2). Both the relative damage coefficient $q$ and the maximum yield loss $m$ were smaller for $M$. vaginalis.

- This can be explained by the strong difference in plant height between the species: rice was able to overtop the $M$. vaginalis plants but not the E. crus-galli plants. However, both weeds had a higher competitive ability than the crop, as the relative damage coefficient $q$ exceeded the value 1 (Kropff \& Spitters, 1991).

The effects of different densities and emergence dates of C. album, P. persicaria and $S$. media on sugarbeet are presented in Fig. 2. Results of fitting Eqns 3 and 5 to the data are given in Table 2. Obviously, $C$. album was the strongest competitor followed by $P$. persicaria. $S$. media reduced yield much less with a relative damage coefficient smaller than 1 , indicating a lower competitive ability than the crop. A significant $(P<0.001)$ reduction in the residual 
(A)
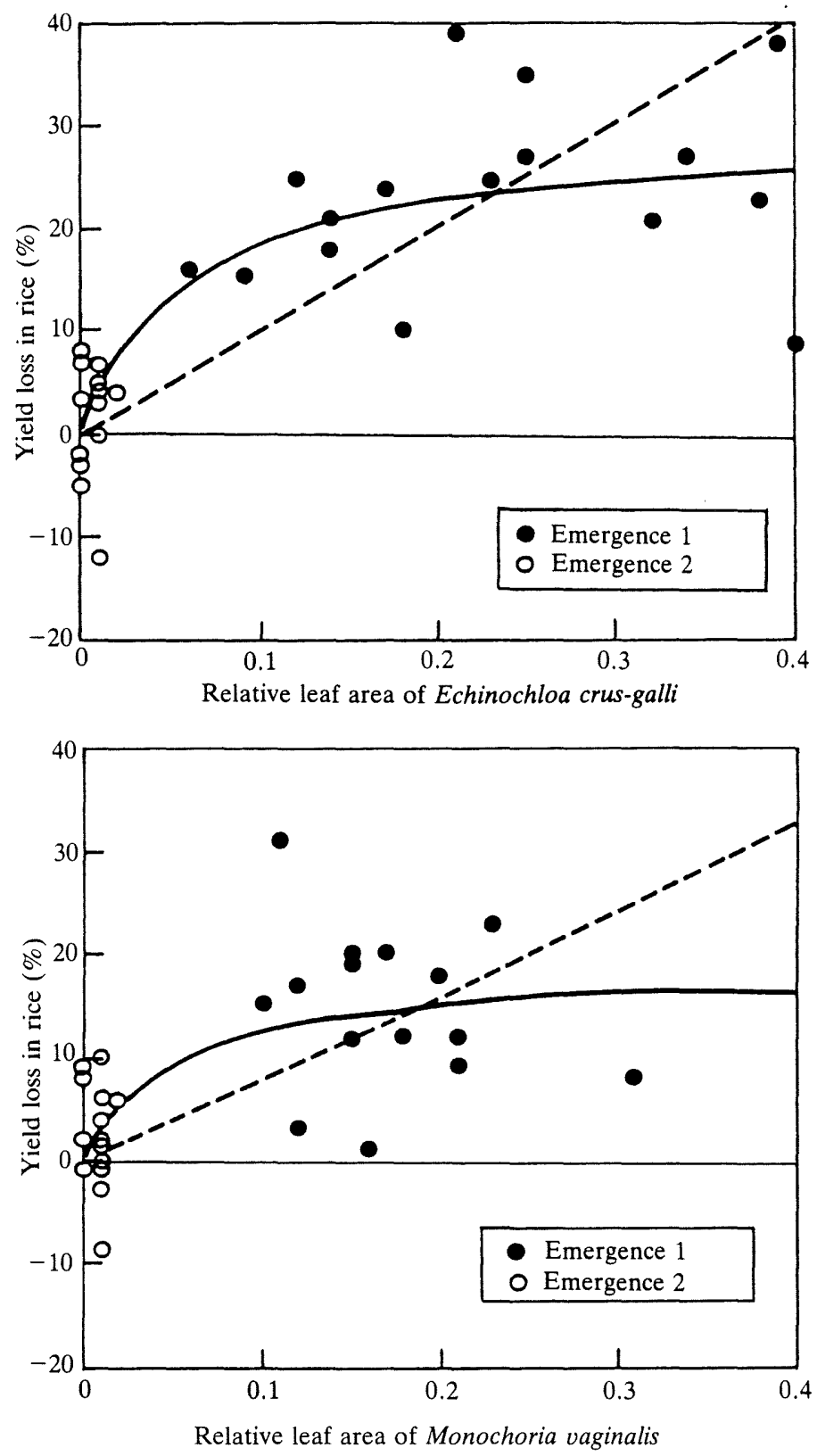

Fig. 1. Yield loss in transplanted rice related to relative leaf area index of Echinochloa crus-galli (A) and Monochoria vaginalis (B), determined 36 days after transplanting. (observed: early emergence weeds 0 ; late emerging weeds $\bigcirc$; fitted with equation $3---$; fitted with equation $5-$-).

sum of squares was observed for $C$. album by introducing the parameter $m$. For $S$. media and $P$. persicaria adding the parameter $m$ to the model did not significantly decrease the residual sum of squares. For $S$. media, however, visual inspection of the graph suggests that the two parameter model provides a more realistic fit to the data. A low maximum yield loss caused by $S$. media can be biologically explained. A short drought period, caused by a 
Table 2. Estimated parameter values using the regression models (Eqns 3 and 5) to fit observed and simulated data sets on competition between tomatoes $(T)$ and $\mathrm{S}$. ptycanthum $(S p)$ for direct seeded $(D S)$ and transplanted $(T P)$ tomatoes, sugarbeet $(S)$ with Chenopodium album $(\mathrm{Ca})$, Stellaria media $(\mathrm{Sm})$ and Polygonum persicaria $(\mathrm{Pp})$ and rice $(R)$ with Monochoria vaginalis $(M v)$ and Echinochloa crus-galli $(E c)$

\begin{tabular}{|c|c|c|c|c|c|c|c|c|}
\hline \multirow[b]{2}{*}{ Experiment } & \multicolumn{2}{|c|}{ Equation 3} & \multirow[b]{2}{*}{$q$} & \multicolumn{5}{|c|}{ Equation 5} \\
\hline & $q$ & $\mathrm{SE}$ & & SE & $m$ & SE & $\mathrm{F}$ & $n$ \\
\hline 1984 TSp DS & 2.54 & 0.07 & 2.48 & 0.08 & 1.01 & 0.01 & 1.9 & 9 \\
\hline 1985 TSp DS & 2.15 & 0.12 & 2.24 & 0.15 & 0.98 & 0.02 & 1.3 & 9 \\
\hline 1984 TSp TP & 3.09 & 0.84 & 16.75 & 6.96 & 0.33 & 0.05 & 20.0 & 9 \\
\hline 1985 TSp TP & 2.94 & 0.73 & 16.34 & 6.73 & 0.35 & 0.05 & 15.0 & 9 \\
\hline $1989 \mathrm{SCa}$ & 46.81 & 9.31 & 66.96 & 16.62 & 0.89 & 0.04 & 5.6 & 18 \\
\hline $1989 \mathrm{SPp}$ & 11.09 & 2.20 & 13.60 & 4.20 & 0.89 & 0.11 & 0.7 & 15 \\
\hline 1989 SSm & 0.36 & 0.10 & 0.83 & 0.53 & 0.31 & 0.16 & 2.0 & 18 \\
\hline $1991 \mathrm{REc}$ & 1.05 & 0.12 & 3.41 & 1.26 & 0.35 & 0.05 & 16.2 & 30 \\
\hline $1991 \mathrm{RMv}$ & 0.73 & 0.12 & 3.50 & 2.65 & 0.18 & 0.04 & 9.7 & 30 \\
\hline
\end{tabular}

delayed irrigation in a dry and hot period, caused premature senescence of the $S$. media in early August, two months before the final harvest of the crop. This enabled the crop to recover. The other species did not show such symptoms, indicating that $S$. media was extremely drought sensitive.

C. album was very competitive in sugarbeet since it strongly overtops sugarbeet causing extreme yield losses at low densities. Maximum sugarbeet height varied between 50 and 60 $\mathrm{cm}$, whereas $C$. album reached a height of $120-150 \mathrm{~cm}$. P. persicaria also overtopped the sugarbeet crop ( $80-100 \mathrm{~cm}$ ), but clearly less than C. album. $S$. media did not overtop the beets $(50-60 \mathrm{~cm})$, but grew about as high as the beets.

The effect of early emerging $C$. album and $P$. persicaria was smaller than the effect of later emerging $C$. album and $P$. persicaria (Fig. 2). This can be understood from the fact that early emerging plants also mature and senesce earlier, enabling the crop to recover partly after the weeds senesce. This was also demonstrated by Kropff (1988) using simulated data on the effect of $C$. album on sugarbeet that showed smaller yield loss at the same relative leaf area index when weeds emerged earlier, since they senesced earlier than the crop. Such effects are strongly determined by the dynamics of the complex competition process, which cannot be explained by simple empirical models like the relative leaf area models. More complex mechanistic models like INTERCOM (Kropff \& Van Laar, 1993) are required for that purpose.

The ability of the model to describe the effects of mixed weed species on crop yield (Eqn $5 a$ ) was analysed by comparing measured yield loss to predicted yield loss using the $q$ and $m$ values of the different weed species as determined from single weed species experiments (Table 2). Fig. 3 shows the relation between predicted and observed yield losses due to the combined effect of $S$. media and $C$. album. Since $C$. album was a much stronger competitor than $S$. media, the trend in calculated yield loss is mainly determined by $C$. album. A tendency to underestimate the effect of late emerging weeds, and to overestimate the effect of early emerging weeds, was observed (Fig. 3). This may be the result of the slightly different effects of early and late emerging $C$. album on maximum yield loss.

Both models were also compared using the data of Weaver et al. (1987) for $S$. ptycanthum in direct seeded and transplanted tomatoes in which a strong difference in maximum yield 


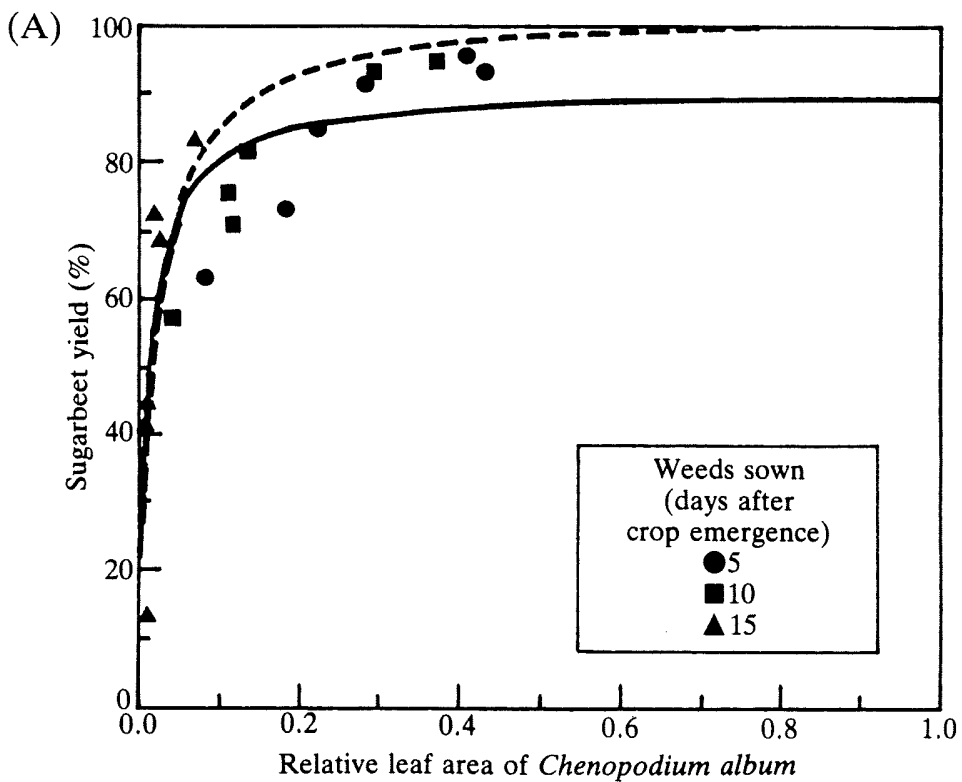

(B)

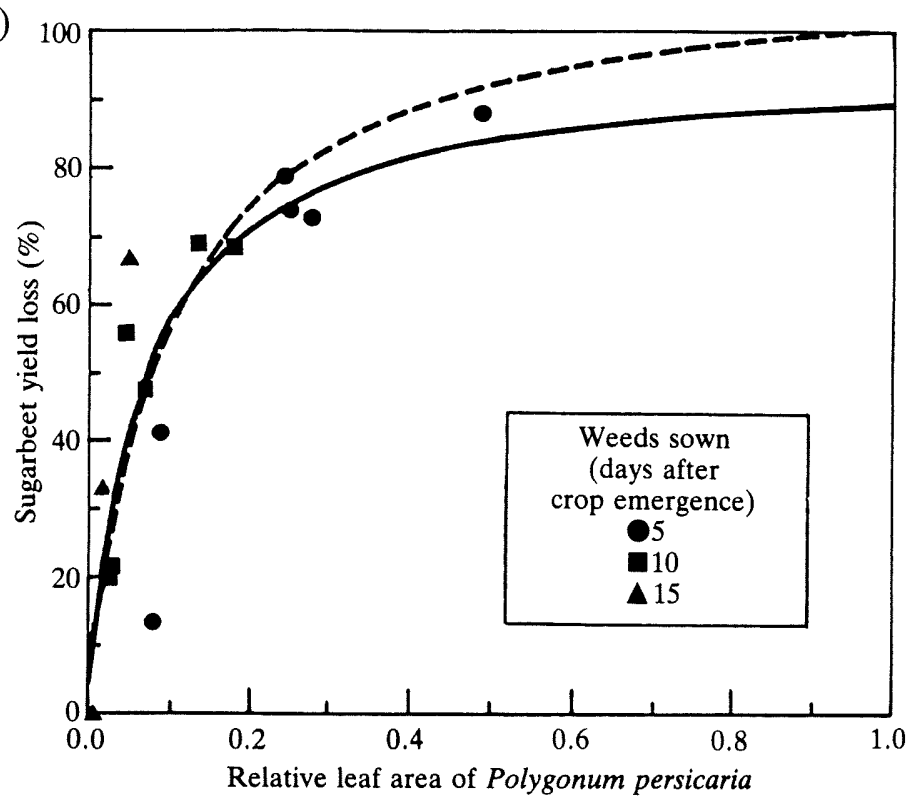

Fig. 2. Yield loss in sugarbeet related to relative leaf area index of (A). Chenopodium album, (B). Polygonum persicaria and C. Stellaria media, determined 23 days after crop emergence in 1990 (observed symbols; fitted with equation $3---$; fitted with equation $5 \longrightarrow$ ).

loss was observed. A graphical analysis of Fig. 4A shows that the data on yield loss and relative leaf area have a quite similar pattern for direct seeded and transplanted tomatoes, whereas the relation between weed density and yield loss was strongly different (Weaver $e t$ al., 1987; Kropff et al., 1992). The $q$ values for direct seeded and transplanted tomatoes were similar for the one parameter model, confirming the visual observation. However, 


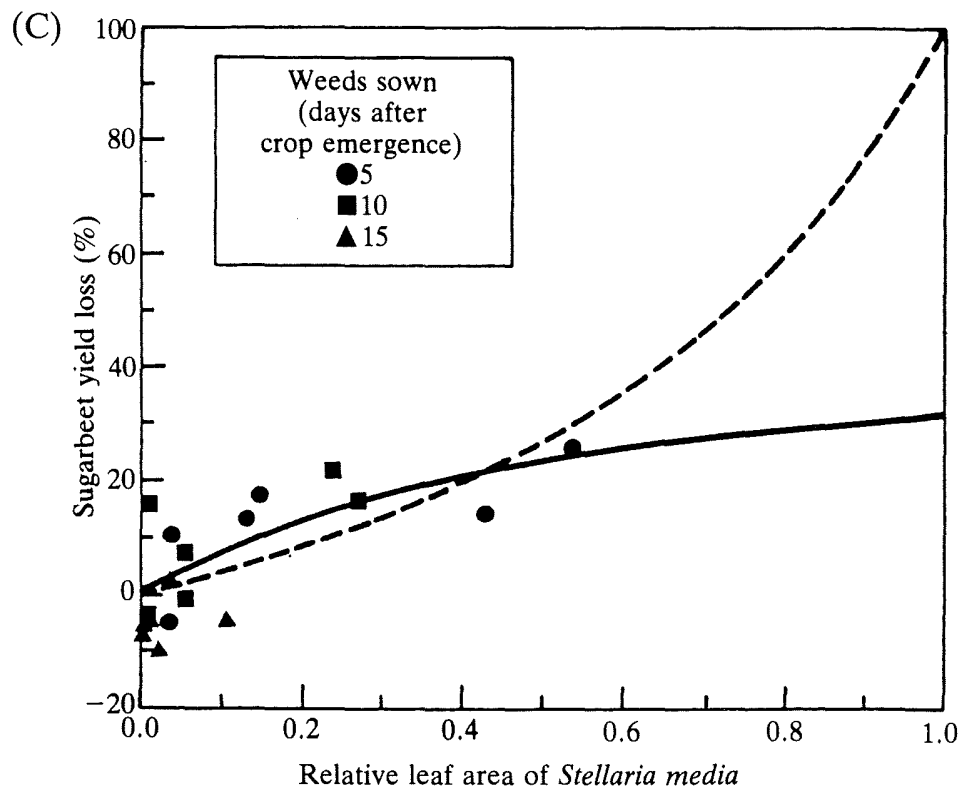

Figure 2C (contd).

when analysed in more detail, and not over the whole range of yield loss between $0 \%$ and $100 \%$ by the two parameter model, different relationships were found. A better description of the data was observed with the two parameter model that indicated a maximum yield loss of about $30 \%$ (Fig. 4B). For direct seeded tomatoes both models resulted in more or less the same curve and the same $q$ value (Fig. 4C).

Inaccuracies in the simulation of the leaf area per plant by an independent eco-physiological model may have caused errors in the estimation of the values for $q$. Because the effect of a transplanting shock was not modelled, the $L A I$ of the crop may have been overestimated, resulting in an overestimation of $q$. However, errors in the simulation of leaf area per plant do not confound the conclusion that a maximum yield loss was observed. The differences in maximum yield loss between the two establishment methods can be biologically explained. Obviously, the weeds in transplanted tomatoes (relatively late emerging weeds), have no ability to reduce total dry matter production by $100 \%$ since much dry matter in the tomatoes has been produced before the weeds started competing (quite some days after weed emergence). Besides that, these weeds are not as competitive as earlier emerging weeds, since they have insufficient resources for strong height and leaf area index development because of competition by the crop. The greater maximum yield loss of seeded compared to transplanted tomatoes reflects the greater competitive ability of $S$. ptycanthum when it emerges at approximately the same time as the crop.

In conclusion, the relative leaf area-yield loss models account for the effect of weed densities, different flushes of the weeds, as well as the period between crop and weed emergence within a limited range of time after crop emergence. However, the introduction of a parameter for maximum yield loss is needed in situations where a maximum yield loss significantly lower than $100 \%$ is observed. A $100 \%$ yield loss at high weed infestations can only be expected when the crop and the weeds compete for the same resources and the weeds are as competitive as the crop or stronger competitors than the crop as in the 


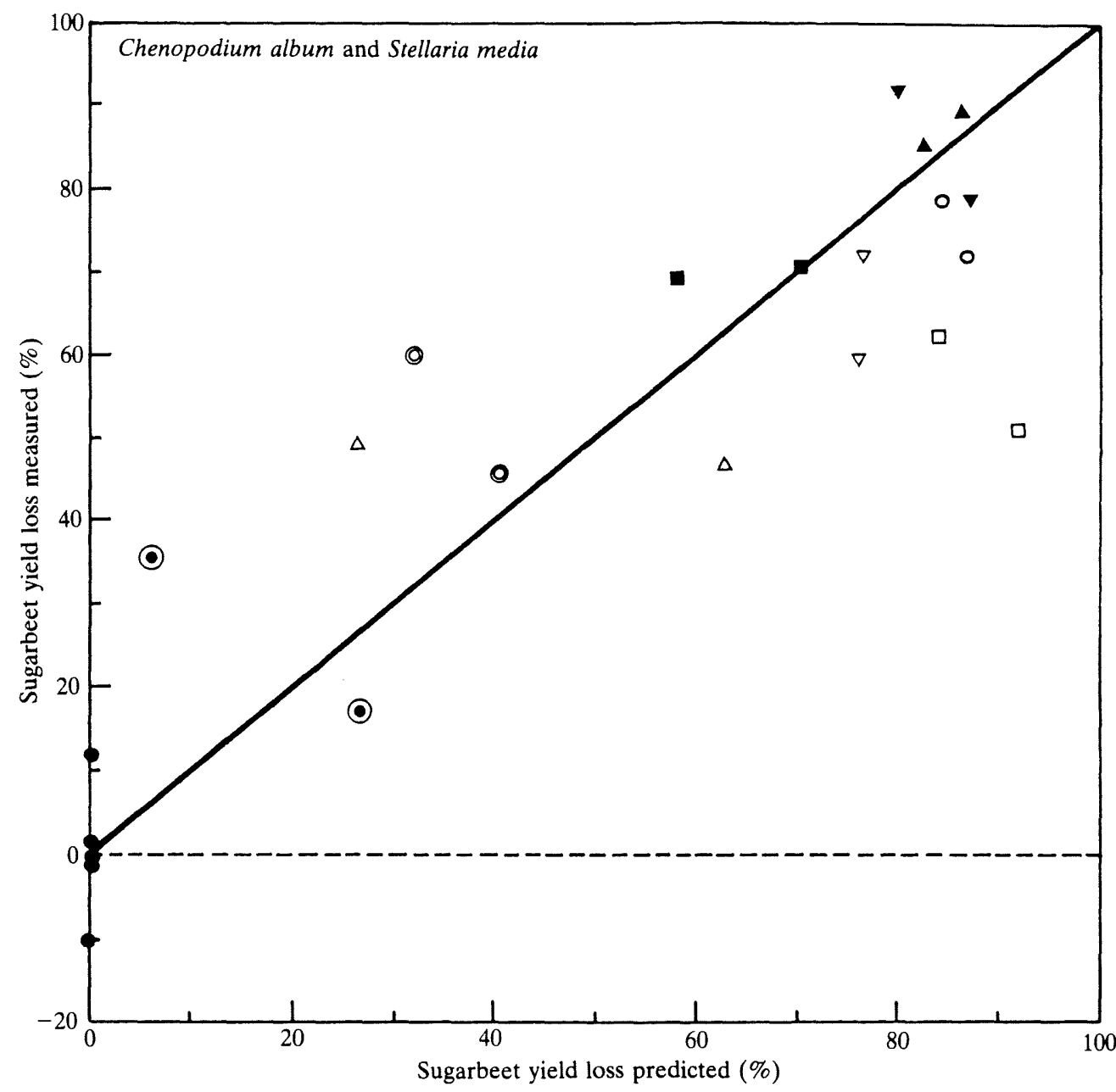

Fig. 3. Relation between observed and calculated (equation $5 a$ with parameters from single weed species treatments) yield loss in a mixture of sugarbeet with Chenopodium album and Stellaria media. Emergence weeds 5 days after emergence: $\square$ (density 1) $\bigcirc$ (density 2) $\nabla$ (density 3); Emergence 10 dae $\triangle$ (density 1$) \nabla$ (density 2$) \boldsymbol{\Lambda}$ (density 3 ); Emergence 15 dae $\odot$ (density 1$) \odot$ (density 2$)$ (density 3 ) (control). Densities were: Density $1: 1.4 \mathrm{Ca} \mathrm{m}^{-2}$ and $1.4 \mathrm{Sm} \mathrm{m}^{-2}$; Density $2: 2.8 \mathrm{Ca} \mathrm{m}^{-2}$ and $5.6 \mathrm{Sm} \mathrm{m}^{-2}$; Density 3: $5.6 \mathrm{Ca} \mathrm{m}^{-2}$ and $44 \mathrm{Sm} \mathrm{m}^{-2}$.

sugarbeet C. album situation. Maximum yield losses that are much less than $100 \%$ can be expected in many crop weed combinations where the crop is a reasonably strong competitor in comparison to the weed or when differences occur in life history, for example, when the weeds emerge late (the crop already produces substantial biomass before competition even starts as in transplanted tomatoes and rice), or when the weeds start to mature early as a result of specific stress (e.g. S. media in this experiment).

Biological interpretation of $\mathrm{q}$ and its dependence on the time of observation

From the derivation of the model (Appendix I) it follows that a value for $q$ exceeding 1 (i.e. $\left.b_{w} / b_{c}>1\right)$ means that adding one weed plant has more effect on the weight of a single 
crop plant than adding one crop plant if the crop and weed have the same leaf area per plant. However, generally the leaf area per plant at any point in time often differs between the competing species because of a different initial leaf area at emergence, a different $R G R L$ or because of a different emergence date. This difference in leaf area per plant between the competing species reflects their competitive ability. Younger weeds with a smaller leaf area per plant at a given point in time cause a smaller yield loss than older weeds. Therefore, the yield loss weed density approach fails to accurately describe the effect of different flushes of weeds with the same parameter values. This is illustrated in Fig. 5, which presents the relation between weed density and yield loss for the effect of $C$. album plants that emerged at three different periods after crop emergence. A much better relationship was found when the relative leaf area was related to yield loss using the same data from Expt 2 (Fig. 2A). Similar results were obtained for the other experiments where the period between crop and weed emergence was varied (data not shown). The advantage of the relative leaf area model over the density approach is that the parameter for the density model ( $a$; Eqn A3) is weighted with the ratio of the leaf area per plant of weed and crop (Eqn A7). Therefore adding younger weed plants, with a lower $a$ value will have the same $q$ value as older weed plants, which makes it possible to use the same $q$ value for weeds emerging at different periods after crop emergence. A value for $q$ exceeding 1 thus means that adding a number of weed plants with the same leaf area index as another number of crop plants at a given point in time has a stronger impact on the yield of a single crop plant than adding the crop plants.

The above indicates that the advantage of the relative leaf area approach is that it takes part of the dynamics of competition (i.e. the relative starting position of the species) into account. However, because the model takes these dynamics into account, a problem arises as well as this weighting procedure leads to a dependence of the value of $q$ to the date of observation, if the ratio between leaf area per plant of the weed and the crop changes in time. When two isolines or identical species are competing, $q$ equals 1 and remains one in time because the $R G R L$ is the same (Eqn 4). However, when the relative growth rate of the leaves is different for the competing species, $q$ will change in time according to Eqn 4 when the plants grow truly exponentially with a fixed $R G R L$. This is illustrated for yield loss in sugarbeet by $C$. album plants that emerged at different periods after crop.emergence and at different densities for two observation dates in Fig. 6. Very good relationships between the relative leaf area of the weeds and yield loss were found for observations at 16 and 42 days after emergence of the crop, but the value of $q$ was different: 52.9 and 10.6, for 16 and 42 days after emergence of the crop respectively. For both observation dates the relation was much better than for the weed density yield loss relationship (Fig. 5) and even the deviations between the results of the observation dates was smaller than the variation found in the weed density plot in spite of the large difference in observation dates and the large difference in the $R G R L$ of $C$. album and sugarbeet.

The predictability of the value of $q$ was determined in more detail for the same crop weed combination. For all three dates of weed emergence the value of $q$ was determined at four observation dates separately using the one parameter model (Eqn 3), which performed better for these (smaller) datasets. The $R G R L$ for sugarbeet was $0.019\left({ }^{\circ} \mathrm{Cd}\right)^{-1}$ and for $C$. album $0.025\left({ }^{\circ} \mathrm{Cd}\right)^{-1}$. Values for $q$ were predicted using Eqn 4 based on the $q_{0}$ for the latest observation date. The results in Fig. 7 show that the time trend in $q$ could be approximated by Eqn 4 . However, because the $R G R L$ in $C$. album was highly variable (the $R G R L$ for the different flushes of the weeds varied from $0.021\left({ }^{\circ} \mathrm{Cd}\right)^{-1}$ to $0.027\left({ }^{\circ} \mathrm{Cd}\right)^{-1}$ data points strongly deviated from the curve in Fig. 7. However, the predicted time trend in the value of $q$ would largely account for the different relations found in Fig. 6 for the two extreme observation dates. 

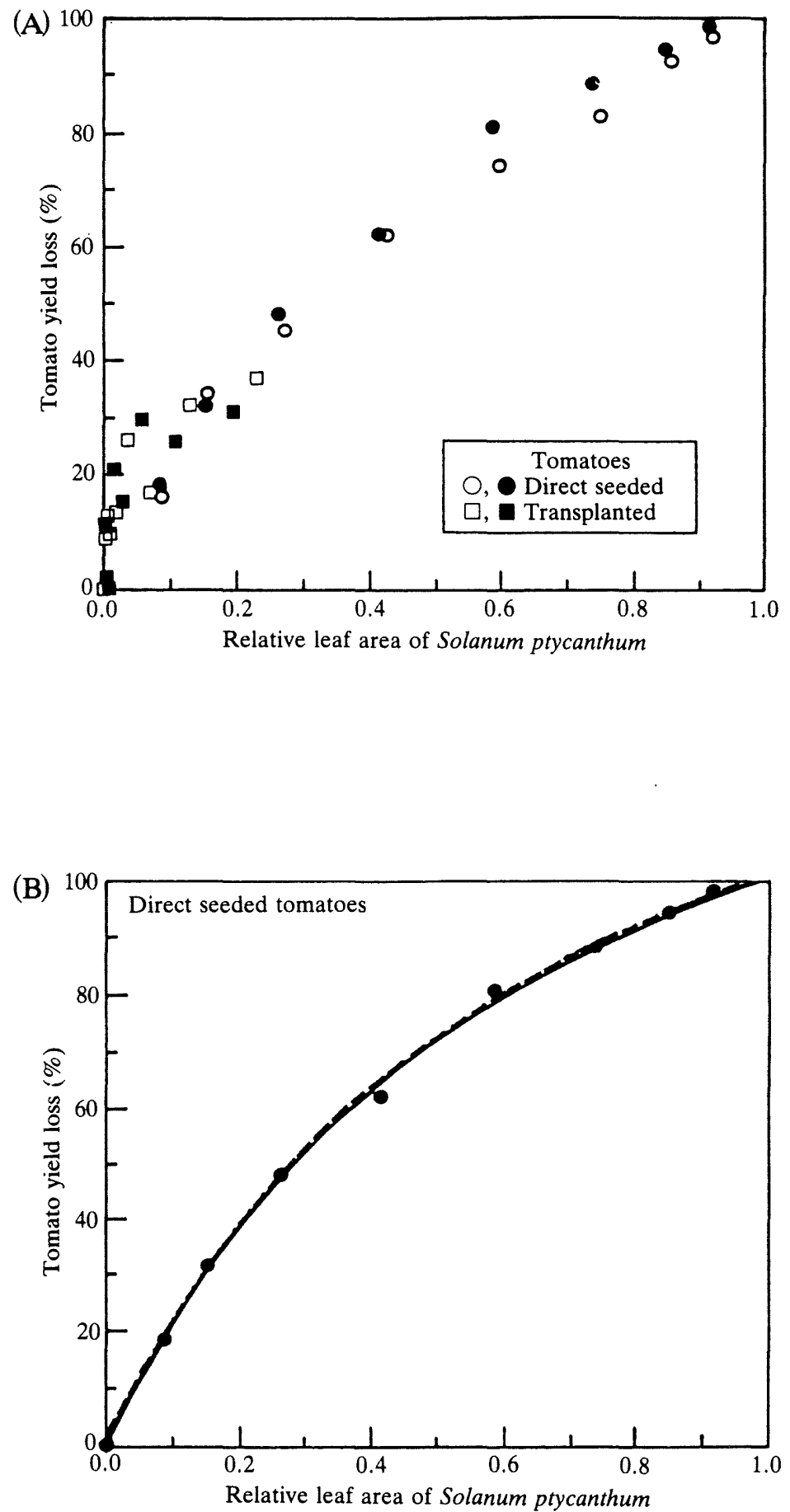

Fig. 4. (A) Yield loss in direct seeded (circles) and transplanted (squares) tomatoes related to relative leaf area index of Solanum ptycanthum, determined $200^{\circ} \mathrm{Cd}$ after tomato seeding or transplanting in 1984 (open symbols) and 1985 (closed symbols); and Yield loss in direct seeded tomato (B) and transplanted tomato (C) related to relative leaf area index of Solanum ptycanthum, determined $200^{\circ} \mathrm{Cd}$ after tomato transplanting in 1984 (data from Weaver et al., 1987) (observed $\mathbf{0}$; fitted with equation 3 $---;$ fitted with equation $5-$ ). 


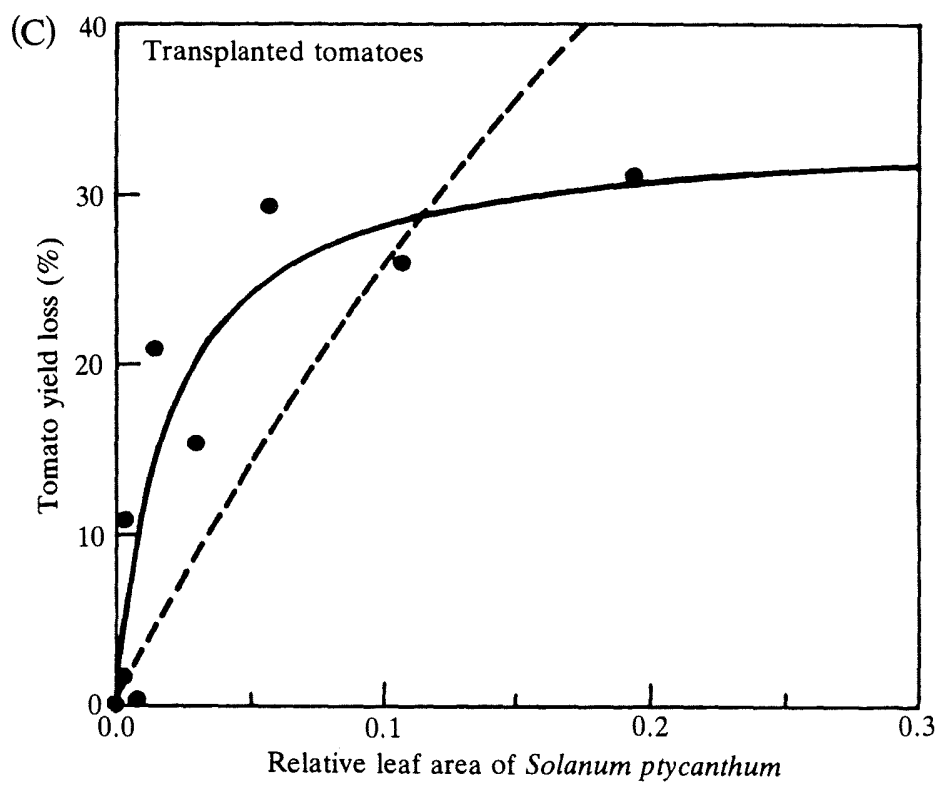

Fig. 4C (contd).

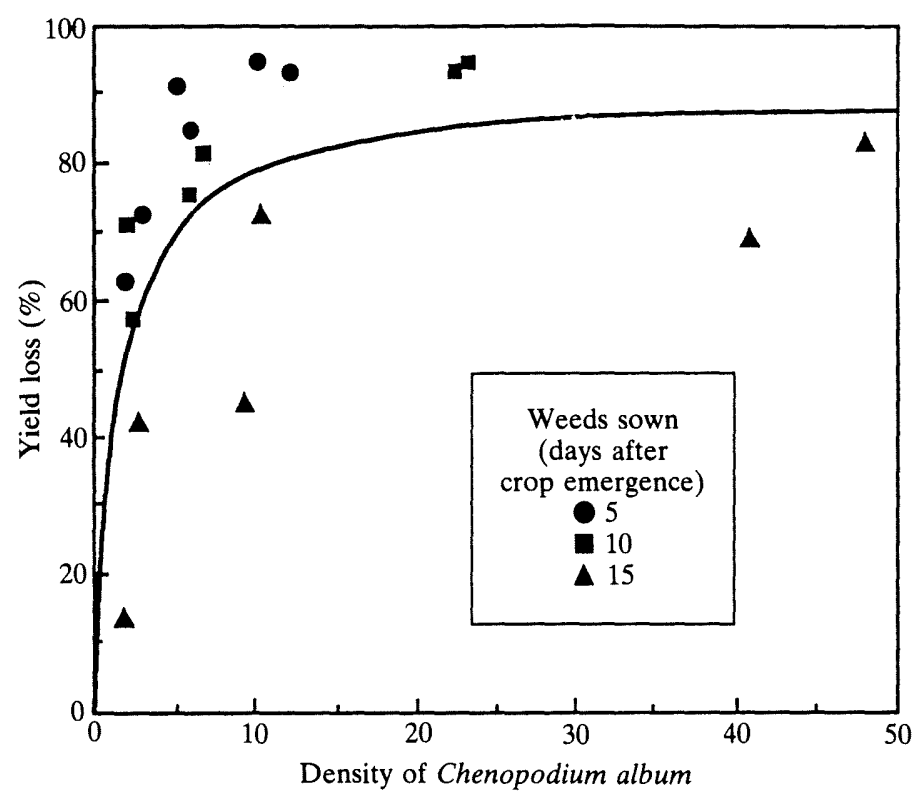

Fig. 5. Yield loss in sugarbeet related to density of Chenopodium album at different dates of weed emergence in 1990 (observed symbols see legend; fitted with equation $2 \longrightarrow$ ). 


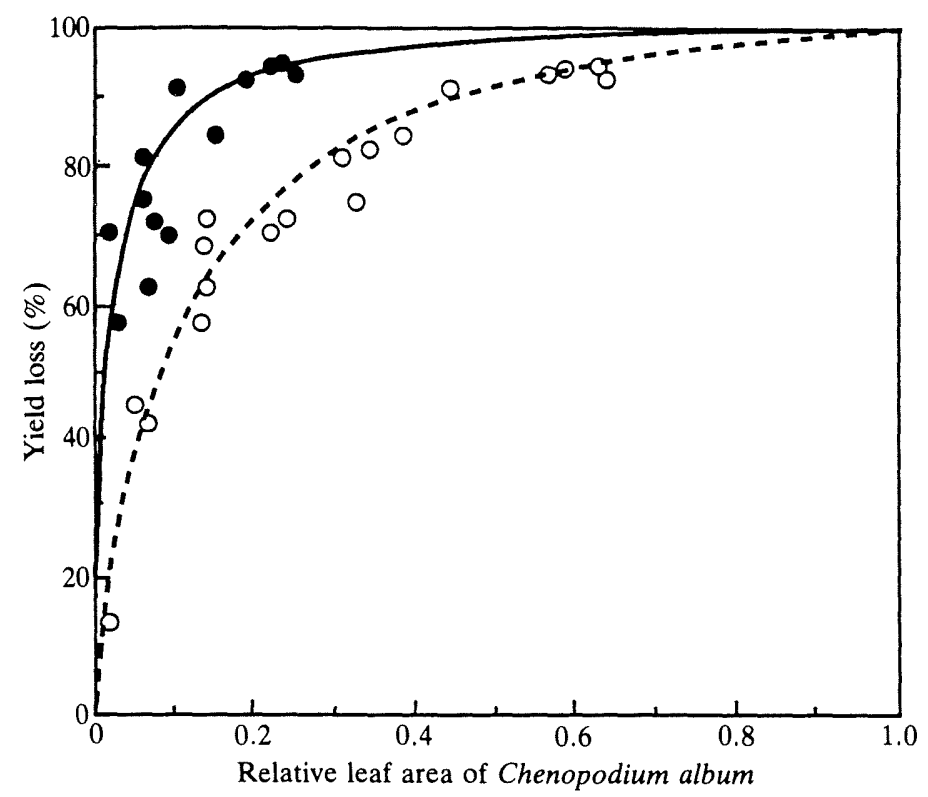

Fig. 6. Yield loss in sugarbeet related to the relative leaf area of Chenopodium album at different dates of observation of the relative leaf area: at 16 days after emergence: squares for observed data and fitted with equation $5 \ldots$; and at 43 days after emergence $(\bigcirc)$ for observed data and fitted with equation 5 $(--)$.

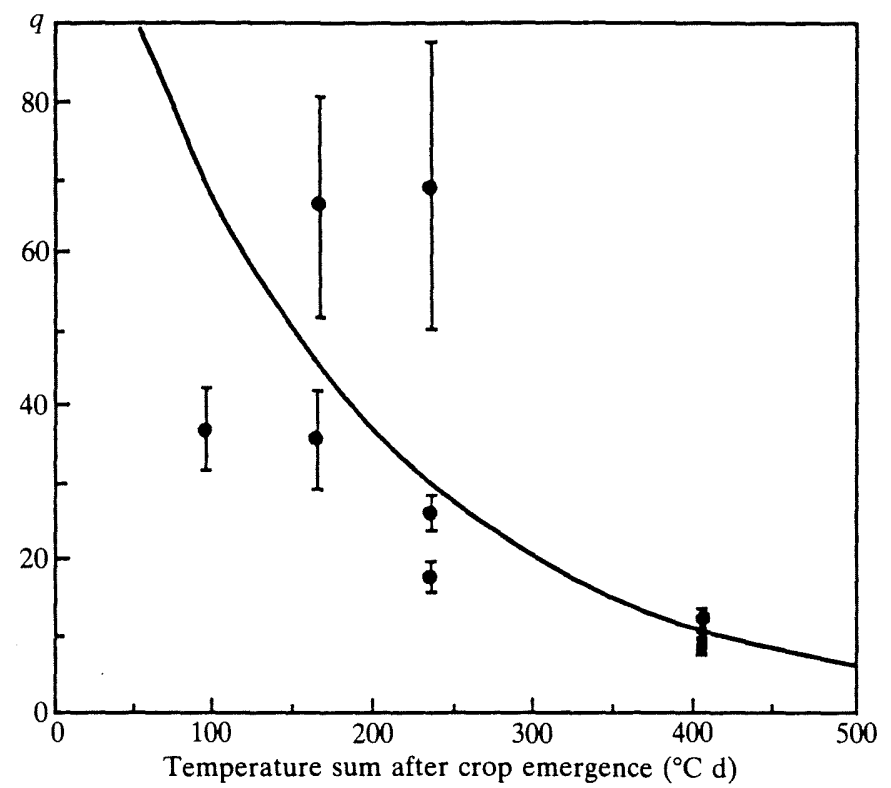

Fig. 7. The estimated value for the relative damage coefficient $q$ for Chenopodium album in sugarbeet at different dates of observation of the relative leaf area (observed: $\bullet$ ), predicted from the value of $q$ at 43 days after crop emergence using Equation 4. 
These results illustrate the complexity of the competition process as a result of its dynamic nature. The relative leaf area model takes a part of those dynamics into account and results in a more accurate description than the weed density model, but a mechanistic understanding of the nature of competition is needed to further improve empirical approaches like the one presented here. The strong sensitivity of the competition process to early growth characteristics of crop and weed plants was also observed in dynamic ecophysiological modelling studies by Kropff \& Van Laar (1993). For this application of predictive models that account for the effect of the period between crop and weed emergence, more insight is needed in early growth processes, so that changes in leaf area per plant and thus $q$ can be more accurately predicted.

In spite of the simplicity of the relative leaf area model, it describes the outcome of the extremely complex competition process reasonably well. Therefore it would be useful to start testing the applicability of the approach for the improvement of integrated weed management systems. Application of the model in practical weed management requires a methodology to estimate relative leaf area in a simple way. Preliminary observations in Expt 2 (data not shown) reveal that relative leaf area can be estimated from estimates of relative leaf cover in the field at early growth stages of the crop. However, careful studies will be needed to study the dynamics of the relation between the relative leaf area and its projection for the major weed and crop species. Lotz et al. (1994) explored options of using remote sensing techniques to estimate relative area of weeds. Their study demonstrated that the potential of that approach differs among crops.

The potential use of the relative leaf area model in practical weed management will be increased when inter specific variation in weed life history, morphology and development can be accounted for by aggregating weeds to groups of problem weeds. The model can be parameterised per species group. Applicability will also be improved by identifying the time window for decision making with respect to specific problem weeds. That will reduce the problem of the time dependence of the parameter $q$.

\section{Acknowledgement}

Part of this work was granted by the EC (EV4C-0020-NL).

\section{References}

Cousens R. 1985. A simple model relating yield loss to weed density. Annals of Applied Biology 107:239-252.

Cousens R, Brain P, O'Donovan J T, O'Sullivan A. 1987. The use of biologically realistic equations to describe the effects of weed density and relative time of emergence on crop yield. Weed Science 35:720-725.

Håkansson S. 1983. Competition and production in short-lived crop-weed stands. Sveriges Landbruks University Report 127. 85 pp.

Kropff M J. 1988. Modelling the effects of weeds on crop production. Weed Research 28:465-471.

Kropff M J, Spitters C J T. 1991. A simple model for crop loss by weed competition on basis of early observation on relative leaf area index of the weeds. Weed Research 31:97-105.

Kropff M J, van Laar H H. Eds. 1993. Modelling Crop-Weed Interactions. Wallingford, Oxon, UK: CAB International; Los Baños, The Philippines: The International Rice Research Institute. 274 pp.

Kropff M J, Weaver S E, Smit M A. 1992. On the use of eco-physiological models for crop-weed competition. 1. Relations between weed density, relative time of weed emergence, relative leaf area index and yield loss. Weed Science 40:296-301. 
Kropff M J, Vossen F J H, Spitters C J T, de Groot W. 1984. Competition between a maize crop and a natural population of Echinochloa crus-galli (L.). Netherlands Journal of Agricultural Science 32:324-327.

Jotz L A P, Kropff M J, Wallinga J, Bos H J, Groeneveld. R W M. 1994. Perspectives of remote sensing techniques to estimate relative leaf areas of weeds in crops for yield loss predictions. Weed Research 34:167-175.

ipitters C J T. 1983. An alternative approach to the analysis of mixed cropping experiments. I. Estimation of competition effects. Netherlands Journal of Agricultural Science 31:1-11.

ipitters C J T, Kropff M J, de Groot W. 1989. Competition between maize and Echinochloa crusgalli analysed by a hyperbolic regression model. Annals of Applied Biology 115:541-551.

Neaver S E, Smits N, Tan C S. 1987. Estimating yield losses of tomato (Lycopersicon esculentum) caused by $S$. ptycanthum (Solanum spp.) interference. Weed Science 35:163-168.

(Revised version received 12 November 1994). 
Appendix I. Derivation of the two parameter model.

The derivation of the two parameter model is similar to the one parameter model as described by Kropff \& Spitters (1991). The starting point in the derivation of the model is the general response of crop yield to plant density, which can often be described by a rectangular hyperbola:

$$
Y_{c m}=\frac{N_{c}}{b_{0}+b_{c} N_{c}}
$$

where $Y_{c m}$ is the yield of the crop in monoculture in $\mathrm{g} \mathrm{m}^{-2}, N_{c}$ is the plant density of the crop in numbers $\mathrm{m}^{-2}$, and $b_{0}$ and $b_{c}$ are the model parameters. The effect of other species (here weeds) can be introduced in this equation in an additive way:

$$
Y_{c w}=\frac{N_{c}}{b_{0}+b_{c} N_{c}+b_{w} N_{w}}
$$

where $Y_{c w}$ is the crop yield in a weedy situation, and $N_{w}$ is the number of weed plants. The parameter $b_{c}$ measures intraspecific competition between crop plants and the parameter $b_{w}$ measures interspecific competition effects of the weeds on the crop.

A simple one parameter expression for yield loss $(Y L)$ as a function of the relative weed density $\left(N_{w} / N_{c}\right)$ can then be derived from Equations 1 and 2 when crop density is constant:

$$
Y L=1-\frac{Y_{c w}}{Y_{c m}}=\frac{a \frac{N_{w}}{N_{c}}}{1+a \frac{N_{w}}{N_{c}}}
$$

where $a$ characterises the competitive effect of the weed on the crop:

$$
a=\frac{b_{w} N_{c}}{b_{0}+b_{c} N_{c}}
$$

Generally, the crop is grown at such densities that monoculture yield $\left(Y_{c m}\right)$ approaches its maximum value, so that the parameter $b_{0}$ (Equation A1) can be neglected. The expression for the parameter $a$ then approaches to:

$$
a=\frac{b_{w}}{b_{c}}
$$

In analogy with the introduction of the parameter $m$ by Cousens (1985) (Equation 2), the parameter $m$ can be introduced in Equation A3:

$$
Y L=1-\frac{Y_{c w}}{Y_{c m}}=\frac{a \frac{N_{w}}{N_{c}}}{1+\frac{a}{m} \frac{N_{w}}{N_{c}}}
$$


This equation can be rewritten by substituting $L A I / L A$ for $N$ (where $L A$ is the average leaf area per plant at the moment of observation and $L A I$ the leaf area index of the weed):

$$
Y L=\frac{a \frac{L A_{c}}{L A_{w}} \frac{L A I_{w}}{L A I_{c}}}{1+\frac{a}{m} \frac{L A_{c}}{L A_{w}} \frac{L A I_{w}}{L A I_{c}}}
$$

- The parameter $q$; the relative damage coefficient is introduced subsequently:

$$
q=a \frac{L A_{c}}{L A_{w}}
$$

as well as the relative leaf area of the weeds $\left(L_{w}\right)$ :

$$
L_{w}=\frac{L \grave{A} I_{w}}{L A I_{c}+L A I_{w}}
$$

which results in:

$$
Y L=\frac{q\left(\frac{1}{\frac{1}{L_{w}}-1}\right)}{1+\frac{q}{m}\left(\frac{1}{\frac{1}{L_{w}}-1}\right)}
$$

which can be rewritten as:

$$
Y L=\frac{q L_{w}}{1+\left(\frac{q}{m}-1\right) L_{w}}
$$

